\title{
Evaluation of 3-mm diameter intravenous tubing for the rapid infusion of fluids
}

\author{
G. D. CROSS \\ Department of Anaesthesia, Odstock Hospital, Salisbury, Wiltshire, England
}

\section{SUMMARY}

The use of intravenous administration systems incorporating 3-mm internal diameter tubing is becoming more common in hospital practice. The maximum flow-rate of crystalloid solutions through 3-mm-diameter tubing is compared to that through conventional 4-mm tubing when connected to standard large-gauge intravenous cannulae.

Lengths of intravenous tubing between $80 \mathrm{~cm}$ and $200 \mathrm{~cm}$ were tested in combination with 16 gauge, 14 gauge and 13 gauge intravenous cannulae.

The results demonstrated that the use of $3-\mathrm{mm}$-diameter infusion sets, or the inclusion of even short lengths of 3-mm tubing in an infusion system, limits the maximum flow that can be delivered through a cannula of size 16 gauge or larger.

The reduced performance of the 3-mm tubing makes administration systems incorporating even short lengths of this diameter of tubing unsuitable in emergency situations and locations where rapid infusion of fluids is vital.

\section{INTRODUCTION}

It is essential that intravenous administration systems allow the rapid infusion of both crystalloid and colloid solutions in situations where emergency fluid resuscitation is required. Intravenous infusion sets incorporating 3-mm internal diameter delivery tubing are being increasingly encountered in hospital and anaesthetic practice, sometimes replacing the more usual 4-mm tubing for general purpose use.

The suitability of these smaller diameter delivery systems to provide rapid infusion rates of crystalloid fluids when connected to standard large-gauge cannulae has not

Correspondence: G.D. Cross, Department of Anaesthesia, Odstock Hospital, Salisbury, Wiltshire SP2 8Bf, England 
previously been investigated. This knowledge is important if giving sets are changed o extension sets incorporating 3-mm tubing are added.

This study examines the maximum flow-rates that can be achieved without the use oq pressure-infusion equipment, through known lengths of 3 and $4 \mathrm{~mm}$ internal diamete tubing when used in conjunction with 16 gauge, 14 gauge and 13 gauge intravenous cannulae.

\section{METHOD}

Plain cut lengths of 3- and 4-mm intravenous tubing, ranging from 80 to $200 \mathrm{~cm}$ i岕 length, were used. All flow-control devices, drip chambers or connecting spikes werg removed. Each length of both 3- and 4-mm tubing was connected, in turn, to a wate reservoir. The water in the reservoir was maintained at a height of $1 \mathrm{~m}$ above the delivery end of the tubing to ensure that the fluid was supplied at a constant pressure Tap water was used for all the experiments as it has a similar viscosity to normal saline응 The water from the fluid reservoir was first run through each plain length of tubing repeated again after a luer lock connector had been added to the delivery end of tubing and, finally, with the luer lock connector in combination with a 16 gauge, 14 gauge an $\Phi$ 13 gauge cannula. The time taken for the delivery of 11 of water was recorded on thre occasions for each length of tubing. The mean time in seconds for the delivery of 11 of water was calculated and expressed in $\mathrm{ml} / \mathrm{min}$.

All tubing connections were made through an outside connector, and the same lyer connector and Wallace $5 \cdot 7-\mathrm{cm}$ intravenous cannulae were used in all tests.

\section{RESULTS}

The results show that the 3-mm tubing has a greater resistance to flow per unit lengt屏 than the 4-mm tubing. This resistance to flow in the $3 \mathrm{~mm}$ tubing is sufficient to prevent the maximum flow of crystalloid solutions through the intravenous cannulae used. Th\& flow was reduced when even short lengths of 3-mm tubing were used.

In Fig. 1, the results have been expressed as a percentage difference in the flow-rate between the 3 - and 4-mm tubing for each cannula.

\section{DISCUSSION}

In clinical practice, a complete infusion set with connecting spike, drip chamber and flow control device will have a slower delivery rate than the test lengths of tubing would indicate. Any factors which increase the resistance to flow in the system, such as additional luer connectors and constrictions from some types of flow control device, wiff further reduce the flow, making the 3-mm system less efficient. 
Table 1 Flow rates in millilitres per minute through the cannulae and tubing combinations ${ }^{1}$

\begin{tabular}{|c|c|c|c|c|c|c|c|c|c|c|}
\hline \multirow{2}{*}{$\begin{array}{l}\text { Tubing } \\
\text { length } \\
(\mathrm{cm})\end{array}$} & \multicolumn{2}{|c|}{$\begin{array}{l}\text { No Luer } \\
\text { lock }\end{array}$} & \multicolumn{2}{|c|}{$\begin{array}{l}\text { Luer } \\
\text { lock }\end{array}$} & \multicolumn{2}{|c|}{13 gauge } & \multicolumn{2}{|c|}{14 gauge } & \multicolumn{2}{|c|}{16 gauge } \\
\hline & $3 \mathrm{~mm}$ & $4 \mathrm{~mm}$ & $3 \mathrm{~mm}$ & $4 \mathrm{~mm}$ & $3 \mathrm{~mm}$ & $4 \mathrm{~mm}$ & $3 \mathrm{~mm}$ & $4 \mathrm{~mm}$ & $3 \mathrm{~mm}$ & $4 \mathrm{~mm}$ \\
\hline 200 & 265 & 631 & 259 & 571 & 204 & 320 & 182 & 253 & 103 & 120 \\
\hline 170 & 297 & 722 & 288 & 618 & 223 & 326 & 189 & 256 & 107 & 120 \\
\hline 140 & 344 & 810 & 326 & 689 & 238 & 340 & 203 & 271 & 109 & 122 \\
\hline 110 & 408 & 923 & 389 & 769 & 263 & 350 & 221 & 279 & 113 & 123 \\
\hline 80 & 499 & 1090 & 465 & 833 & 288 & 370 & 237 & 291 & 118 & 123 \\
\hline
\end{tabular}

'Nominal maximum flow rates for the cannulae used as quoted by the manufacturer: $16 \mathrm{Gauge,} 121 \mathrm{ml} / \mathrm{min}$; 14 Gauge, $251 \mathrm{ml} / \mathrm{min} ; 13$ Gauge, $326 \mathrm{ml} / \mathrm{min}$.

The large flow rates through the 3-mm tubing alone or with a luer lock connector would suggest that the demands of any intravenous catheter should be met. When the 3-mm tubing is connected to a cannula, the manufacturers quoted maximum capacity is never reached with a progressive reduction in flow as the tubing length increases. It is important to note that the average length of tubing on an administration set lies between $150 \mathrm{~cm}$ and $200 \mathrm{~cm}$

The final flow rate may be increased by a direct effect of raising the perfusion pressure as predicted from the Poiseuille equation, providing the flow remains laminar:

$$
\begin{aligned}
& \mathrm{Q}=\text { Flow rate } \\
& \mathrm{P}=\frac{\pi \mathrm{Pr}^{4}}{\mu 8 \mathrm{~L}} \quad \begin{array}{l}
\mathrm{L}=\text { Lengtied pressure } \\
\mu
\end{array} \quad \begin{array}{l}
\mu \text { Viscosity } \\
\mathrm{r}=\text { Radius of the tubing }
\end{array}
\end{aligned}
$$

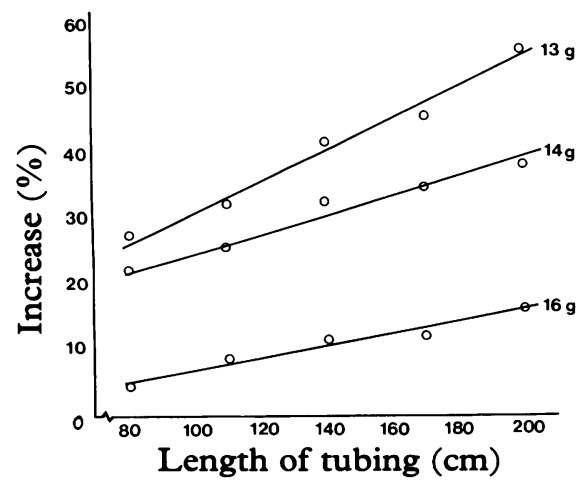

Fig. 1 Percentage increase in flow rate of 4-mm tubing as compared to 3-mm tubing for the cannulae shown. 
The increase in perfusion pressure can be achieved either by raising the height infusion above the level of venous access or by the use of pressure infusion equipment (Dula et al., 1981). Although the use of such equipment will achieve high infusion rate (Mateer et al., 1985), it is not always available or easily applied in the emergenç situation, and is inappropriate where glass bottled solutions are used.

The increased viscosity of plasma substitutes, albumin solutions and blood wit reduce the flow rates further as an inverse function of their viscosity. When it $\bar{p}$ necessary to rapidly transfuse a viscous intravenous fluid such as blood, other workers have suggested tubing with an internal diameter of greater than $4 \mathrm{~mm}$ or $5 \mathrm{~mm}$ be employed. Both a urological fluid administration set (Nadeau \& Tousignant, 1985) and 6.4-mm internal diameter tubing (Mateer et al., 1985) have been used.

The suitability of systems containing even short lengths of 3-mm-diameter tubing must be questioned in certain locations, because of their reduced performance. Rap infusion rates are routinely required during fluid resuscitation in casualty departments. surgical emergencies, anaesthetic work and obstetric practice. Large-gauge cannulae are designed to deliver rapid infusion rates and are used in these emergency situations. Thas makes it essential that large-gauge cannulae should not be connected to a 3-mm infusiog

Table 2 Internal diameter measurements of available fluid administration sets and some additional intravenous tubing and taps

\begin{tabular}{|c|c|c|}
\hline \multicolumn{3}{|c|}{ Solution administration sets } \\
\hline Avon & A26 & $3.0 \mathrm{~mm}$ \\
\hline Boots & Steriflex & $3.0 \mathrm{~mm}$ \\
\hline \multirow[t]{2}{*}{ Braun } & Accudrop & $3.0 \mathrm{~mm}$ \\
\hline & Intrafix & $3.0 \mathrm{~mm}$ \\
\hline Mallinckrodt & $91269-2$ & $3.0 \mathrm{~mm}$ \\
\hline Travenol & $\mathrm{C} 0334$ & $3.0 \mathrm{~mm}$ \\
\hline \multicolumn{3}{|c|}{ Blood administration sets } \\
\hline Avon & A100 & $4.0 \mathrm{~mm}$ \\
\hline Braun & Sangofix & $4.0 \mathrm{~mm}$ \\
\hline Travenol & $\mathrm{C} 0271$ & $4.0 \mathrm{~mm}$ \\
\hline \multicolumn{3}{|c|}{ Extension tubing } \\
\hline Avon & A60 & $4.0 \mathrm{~mm}$ \\
\hline Braun & & $3.0 \mathrm{~mm}$ \\
\hline \multirow[t]{2}{*}{ Mallinckrodt } & 91133 to 36 & $2.3 \mathrm{~mm}$ \\
\hline & 91140 to 43 & $2.7 \mathrm{~mm}$ \\
\hline Travenol & $\mathrm{C} 0057$ & $4.0 \mathrm{~mm}$ \\
\hline Viggo & Connecta & $2 \cdot 2 \mathrm{~mm}$ \\
\hline Vigon & 220 series & $2.5 \mathrm{~mm}$ \\
\hline \multicolumn{3}{|c|}{ Fluid-warming coils (Diameter of main section } \\
\hline Avon & A80 & $4.0 \mathrm{~mm}$ \\
\hline Portex & $200 / 700$ & $4.0 \mathrm{~mm}$ \\
\hline Travenol & $\mathrm{C} 2410$ & $2.8 \mathrm{~mm}$ \\
\hline \multicolumn{3}{|c|}{ Taps and stopcocks (Diameter of narrowest lumen) } \\
\hline Braun & Discofix-3 & $1.8 \mathrm{~mm}$ \\
\hline Mallinckrodt & 91045 & $1.7 \mathrm{~mm}$ \\
\hline Vigon & 876.00 & $1.9 \mathrm{~mm}$ \\
\hline Viggo & $4614-4$ & $1.8 \mathrm{~mm}$ \\
\hline
\end{tabular}


system which cannot deliver large flows of even crystalloid solutions. When required, short lengths of 3-mm or smaller-diameter tubing found on some extension sets and infusion ramps must be removed.

\section{CONCLUSION}

Intravenous infusion systems containing lengths of 3-mm internal diameter tubing, in combination with large-gauge intravenous cannulae, should be avoided in locations where high flow-rates are to be achieved without the use of pressure-infusion equipment.

\section{ACKNOWLEDGEMENT}

The author acknowledges Dr R.F. Barrett and Mr J. M. Porter for their help in preparation of the manuscript.

\section{REFERENCES}

Dula D. J., Muller H. A. \& Donovan J. W. (1981) Flow variance of commonly used I.V. infusion techniques. Fournal of Trauma 21, 480-2.

Mateer J. R., Thompson B. M., Tucker J., Aprahamian C. \& Darin J. C. (1985) Effects of high infusion pressure and large-bore tubing on intravenous flow rates. American fournal of Emergency Medicine 3, 1879.

Nadeau S. \& Tousignant M. (1985) The use of a urologic set for improved fluid administration rates. fournal of the Canadian Anaesthetic Society 32, 283-6. 